\title{
Randomized Controlled Trials and Case Reports: Two Sides of the Same Coin?
}

\author{
Nikolaos G. Evangelatos Marina P. Siakantaris \\ First Department of Internal Medicine, Medical School, University of Athens, Greece
}

The epistemological status of medicine has long been a field of debate for philosophers of science and physicians as well. Many consider medicine to be a genus concept such as philosophy, history, art and science while others consider medicine to be a species concept, subjected to a wider genus proximum, science. Depending on which concept a scholar chooses to adopt when studying such an equivocal and complicated issue, the methodology and results of the research differ. This also applies to the medical practice, since physicians think and act in the context of a Kuhnian paradigm which, in our era, is the so-called biomedical model.

In recent years, medicine has experienced an epistemological 'shock' and has transformed from an art to a science. The most important method of contemporary medical science is the adoption of randomized controlled trials (RCTs) as a tool to test theories and hypotheses against empirical evidence [1]. However, the 'pyramid of truth' consists not only of RCTs but also of case reports, a fact that weaknesses the scientific character of modern medicine, since it distinguishes it from basic sciences such as physics.

Either based on the Popperian perception of science [e.g., 2] or on the French structuralism and post-structuralism [e.g., 3], the methodology of modern medicine is subjected to criticism. Indeed, the scientific objects of every study should be interchangeable, as is the case in physics. When we test the law of gravity against empirical evidence, studying the fall of mass ' $m$ ' from height ' $h$ ' is the same whether ' $m$ ' refers to an apple or a piece of iron. As we can easily understand, this is not true with case reports. It is totally different to study the course of a disease in a Caucasian or an Afro-American, an adult or a child, a man or a woman. Taking into consideration that RCTs consist of cohorts of case reports, we conclude that RCTs and case reports share the same epistemological problem. Those who design RCTs try carefully to address these problems by applying strict criteria concerning the eligibility of the candidates for the study, in an attempt to render them interchangeable. However, these criteria do not deal with the core problem. Males are less different to each other than to females. However, males are not $100 \%$ equal. On the contrary, mass ' $\mathrm{m}$ ' whether it refers to an apple or a piece of iron, remains $100 \%$ mass ' $\mathrm{m}$ ', rendering physics with the (conventional) Popperian criteria $100 \%$ science. The question remains the same. Is medicine a science or does it have a different epistemological status than physics?

Although the number of case reports in the literature has markedly decreased (possibly another sign of the social origin of the transformation of medicine to science), the very existence of unique cases in daily medical practice is another proof of the epistemological differences between medicine and basic sciences [4]. The scope of medicine is not only the acquisition of new knowledge through RCTs but, foremost, the effective treatment and cure of every single case. It is necessary to understand that being more scientific does not necessarily mean being better or more efficient. After all, doctors know that the best doctor is not the one with many scientific publications but the one that patients remember most.

\section{References}

1 Sackett DL, et al: Evidence based medicine: What it is and what it isn't. BMJ 1996;312:71-72.

2 Popper K: The Logic of Scientific Discovery, rev. London, Routledge, 1992.

3 Bachelard G: The Formation of the Scientific Mind. Manchester, Clinamen, 2002.

4 Canguilhem G: The Normal and the Pathological. Cambridge, MA, Zone Books, 1991.

\section{KARGER}

Fax +497614520714

Information@Karger.de

www.karger.com (c) 2009 S. Karger GmbH, Freiburg

Accessible online at:

www.karger.com/fok
Nikolaos G. Evangelatos, MD

First Department of Internal Medicine

Medical School, University of Athens,

Agiou Thoma 17, Athens, Greece,

Tel. +30 2107774705 , Fax 7788830

nevagel@med.uoa.gr 